Association for Information Systems AIS Electronic Library (AISeL)

ICIS 1988 Proceedings

International Conference on Information Systems

1988

\title{
SOCIAL DETERMINANTS OF INFORMATION SYSTEMS USE
}

David C. Robertson

Massachusetts Institute of Technology

Follow this and additional works at: http://aisel.aisnet.org/icis 1988

\section{Recommended Citation}

Robertson, David C., "SOCIAL DETERMINANTS OF INFORMATION SYSTEMS USE" (1988). ICIS 1988 Proceedings. 8. http://aisel.aisnet.org/icis1988/8

This material is brought to you by the International Conference on Information Systems (ICIS) at AIS Electronic Library (AISeL). It has been accepted for inclusion in ICIS 1988 Proceedings by an authorized administrator of AIS Electronic Library (AISeL). For more information, please contact elibrary@aisnet.org. 


\title{
SOCIAL DETERMINANTS OF INFORMATION SYSTEMS USE ${ }^{1}$
}

\author{
David C. Robertson \\ Center for Information Systems Research \\ Sloan School of Management \\ Massachusetts Institute of Technology
}

\begin{abstract}
The use of information systems (IS) is determined by many factors, such as the usability and usefulness of the system, the tasks facing the user, the training and background of the user, and the social group of which the user is a part. Much of the "impacts" research has ignored social and political factors, and the results in this area reflect this bias.

This point can be illustrated by examining the literature on the impacts of information systems on different organizational variables. The research on the impact of IS on the quality of work life (QWL), for example, has shown that IS can decrease QWL, increase QWL, both increase and decrease QWL, or have no effect. Similarly mixed results have been found for centralization of authority, number of levels of reporting relationships, and other dimensions of organizational structure.

It is understandable that much research on the impact of information systems on organizations has had mixed and even contradictory results. Poor research methods, different operationalizations of the same variables, different levels of analysis, and inadequate theory are all partly responsible for the variance in results. It is argued that the lack of convergence in the results is also due to a fundamental assumption behind some impacts research: that the features of an IS alone can cause any impact to occur. Impacts are mixed because organizational contexts are mixed, and it is the interaction of the organization and the information system that ultimately determines the impact of that system. Thus, the mixed impacts research results can be viewed as a replicated finding: the same type of system can have different impacts in different organizations.
\end{abstract}

Information systems are not objective immutable objects applied to clearly defined tasks. When an information system is introduced into an organization, the process whereby an individual determines where and how to use an IS is, of course, influenced by the features of that IS, yet the individual's usage will also be affected by the social group around that individual. A major question, then, is by what mechanism this social effect occurs.

There are two ways the social group can affect the way an individual uses a system:

- By affecting how the individual interprets the system. Initially, the social group will influence the manner in which an IS is used by affecting the way the individual interprets the system (i.e. when and how he or she uses the system). The social group, when faced with a new technology, will experiment with it and form ideas about which tasks it should or shouldn't be used to solve. The usage of a new IS (and the ultimate impact of that system) is not determined solely by the features of the IS nor the opinions of those in the social group using the system. Rather these two factors interact to determine the proper role of the IS in the social group.

- By the social pressures and demands from the group on the individual to use the system. These can arise from requests to use a particular system from others working on interdependent tasks, or required IS usage by supervisors. Also, if an individual's rivals in the firm are using a new system, then the system may be used out of fear, envy, or curiosity.

The results of the impacts literature are mixed because these impacts are the result of the usage of IS, which is idiosyncratically affected by both the interpretation process that occurs within the social systems using the IS, and the social demands and pressures on individuals using the IS. In the current research, these social influences are operationalized and measured through the concept of structural equivalence.

Structural equivalence is a measure of similarity in interaction patterns. If two people work with the same others, go to the same others for technical and administrative help, and report to the same person, then the two are structurally equivalent (with respect to those relationships). Two or more structurally equivalent individuals can be said to occupy the same structural position. 
Structural equivalence analysis aggregates "who to whom" relational data to distill overall interaction patterns. The interaction between any two structural positions $\mathrm{A}$ and $\mathrm{B}$ is thus a good estimate of the interaction between any individual in position A and any in position B. The social structure revealed reflects the informal structure of the organization--the actual pattern of interactions between organizational members. To understand the link between an individual's structural position and his or her IS usage, three research questions were generated:

- Is structural equivalence related to IS usage through interpretation? Do structurally equivalent individuals use systems similarly because they interpret them similarly?

- Is structural equivalence related to IS usage through role pressures and demands (which will include pressures and demands to use an information system)?

- Is structural equivalence related to competence? Individual competence is expected to be matched with task assignment. Individuals with similar task assignments would use IS in similar ways.

The research question was analyzed by studying the social network of an organization and the usage patterns for five PC-based software packages. The organization studied was one branch of a large information systems consulting firm.

The data show that an individual's usage of an information system was significantly related to the individual's structural position for four of the five IS studied. It can be inferred from the data that structural equivalence is linked to individual IS interpretation for only the newest system. Role pressures and demands are related to the usage of three other IS, and the hypotheses related to individual competence received no support.

An inference to be drawn from the data is that, for new systems, there is a variance in the beliefs about where and how an IS should be used around this organization. That there exist different local interpretations of the same system this author believes is positive, as long as the interpretations do not vary too widely. Widely varying interpretations will lead to conflict and inefficient use of the technology. No variation in interpretations presents a drawback of a different sort: innovation comes from allowing different interpretations to flourish and encouraging the spread of especially valuable ones through the firm. A balance must be maintained between too much and too little variation in interpretations if information systems are to be used effectively. Thus it is important that mechanisms be put in place to facilitate the sharing of new applications around the organization. Such mechanisms as user groups, internal or external consultants, or rotation of personnel can be used to diffuse new information systems.

Another conclusion to be drawn is that, for existing systems, usage patterns may vary along structural positions. Thus, to change the organizational usage patterns, it is necessary to change the usage patterns within each structural position. This can be a difficult process, as structural positions can cut across both titles and functions.

Usage of an information system is the moderating variable through which information systems impacts occur. If it is true that the usage of information systems is determined by the interplay of the features of the information system and the characteristics of the organization, then the focus of impacts research must shift to include both in any analysis. In fact, what must be considered is not either the IS or the organization, but the relationship between the two. The unit of analysis should no longer be the information system nor the organization, but the information system with respect to a particular organization. No longer should an information system be described as "easy to use," but rather "easy to use in organization X."

The individual using an information system does not act in a vacuum. The individual's use of a system will be affected by the opinions and actions of those around him or her. Structural position was linked to two such effects: the interpretation of new systems, and demands and pressures to use existing systems. Structural equivalence analysis thus appears to be a promising area for future research.

\section{ENDNOTES}

1. This paper has been accepted for publication by Joumal of MIS. 